\title{
Planejamento urbano participativo e gestão democrática em Palmas (TO) à luz da democracia deliberativa
}

\author{
Participatory urban planning and democratic management in Palmas \\ (TO) according to the deliberative democracy
}

Sarah Afonso Rodovalho[a] [D, Mônica Aparecida da Rocha Silva[b] [D],

Waldecy Rodrigues $[$ [b] iD

[a] Universidade Federal do Tocantins (UFT), Curso de Arquitetura e Urbanismo, Programa de Pós-Graduação em Desenvolvimento Regional, Palmas, TO, Brasil

[b] Universidade Federal do Tocantins (UFT), Curso de Ciências Econômicas, Programa de Pós-Graduação em Desenvolvimento Regional, Palmas, TO, Brasil

Como citar: Rodovalho, S. A., Silva, M. A. R., \& Rodrigues, W. (2019). Planejamento urbano participativo e gestão democrática em Palmas (TO) à luz da democracia deliberativa. urbe. Revista Brasileira de Gestão Urbana, v. 11, e20190072. https://doi.org/10.1590/2175-3369.011.e20190072

\section{Resumo}

Este estudo parte do pressuposto que a teoria da democracia deliberativa de Evans (2003) dialoga com a prática do planejamento urbano participativo e da gestão democrática das cidades preconizados pelo Estatuto da Cidade, que tem no Plano Diretor Participativo o principal instrumento de desenvolvimento urbano nos municípios. Neste sentido, este artigo busca apresentar, à luz da democracia deliberativa, como se deram os processos de planejamento urbano participativo e gestão democrática em Palmas, na elaboração, aprovação e implantação do Plano Diretor Participativo de Palmas (TO). Metodologicamente, foram realizadas pesquisas bibliográfica e documental, que colocaram em diálogo o conceito de democracia deliberativa e as determinações do Estatuto da Cidade quanto ao planejamento urbano participativo e da gestão democrática. Foram analisados os documentos de elaboração do Plano Diretor Participativo de Palmas (PDPP), o documento de análise do Lei Complementar nº 155/2007 realizada pelo Instituto Municipal de Planejamento Urbano de Palmas (IMPUP) e outras leis municipais. Deste modo, foi possível concluir que a metodologia de elaboração do PDPP se enquadrou em uma prática de planejamento urbano participativa, concebendo instituições de democracia deliberativa por meio das reuniões e audiências públicas. No entanto os espaços de gestão democrática não se consolidaram, inviabilizando uma governança fortalecida pela participação.

Palavras-chave: Democracia deliberativa. Planejamento urbano participativo. Gestão democrática. Plano Diretor Participativo. Palmas (TO).

\footnotetext{
Abstract

SAR é arquiteta e urbanista, doutoranda em Desenvolvimento Regional, e-mail: sarahrodovalho@uft.edu.br MARS é cientista social, doutora em Ciências Sociais, e-mail: monicars@uft.edu.br

WR é economista, doutor em Estudos Comparados de Desenvolvimento, e-mail: waldecy@terra.com.br
}

This study assumes that Evans's theory of deliberative democracy (2003) is related to the practice of participatory urban planning and the democratic management of cities recommended by the City Statute, 
which in the Participative Master Plan is the main instrument of urban development in counties. In this sense, this article seeks to present, in the light of participatory democracy, the processes of participative urban planning and democratic management of Palmas, in the elaboration, approval and implementation of the Palmas Participatory Master Plan (TO). Methodologically, bibliographical and documentary research was carried out, which put into dialogue the concepts of deliberative democracy and the determinations of the City Statute regarding participatory urban planning and democratic management. The documents for the formulation of the Participatory Urban Plan of Palmas (PUPP), the analysis of the Supplementary Law 155/2007 document by the Municipal Institute of Urban Planning of Palmas (MIUPP) and others municipal laws were analyzed. In this way, it was possible to conclude that the PUPP elaboration methodology was part of a participatory urban planning practice, designing institutions of deliberative democracy through meetings and public hearings, but the spaces of democratic management did not consolidate, making a governance strengthened by participation impossible.

Keywords: Deliberative democracy. Participatory urban planning. Democratic management. Participatory Urban Plan. Palmas (TO).

\section{Introdução}

O ponto de partida comum das diversas abordagens institucionais é a alegação de que as instituições importam e que a compreensão das instituições é fundamental para entender os processos de mudança social e de desenvolvimento (North, 1990; Hollingsworth, 2000, Nee, 2005; Hall \& Taylor, 2003; Evans, 2003; Tang, 2011). O institucionalismo sociológico, em especial, busca explicar o processo de desenvolvimento das instituições por meio das questões sociais, históricas e culturais e enfatiza principalmente a lógica da reprodução institucional, a partir da constituição de regras, normas, valores, rituais e rotinas (Sousa, 2014). A definição de instituição, nesse caso, envolve não só as regras, procedimentos ou normas formais, mas também os sistemas de símbolos, os esquemas cognitivos e os modelos morais que fornecem padrões de significados e guiam a ação humana. Assim, rompe com a dicotomia conceitual entre instituição e cultura e tende a redefinir os dois conceitos como sinônimos, como uma rede de hábitos, de símbolos e de cenários que fornecem modelos de comportamento (Hall \& Taylor, 2003).

Este artigo parte do pressuposto que o estudo das instituições importa também para compreender os processos de desenvolvimento urbano, entendendo-se o desenvolvimento urbano "como a mudança social positiva da e na cidade" (Souza, 2010, p. 40). Para Souza (2010), o desenvolvimento deve ser entendido como uma mudança social positiva, de conteúdo atrelado aos desejos e expectativas de grupos sociais concretos, considerando seus valores culturais e particularidades histórico-geográficas.

No entendimento aqui defendido, é possível compreender a Política Urbana no Brasil, regulamentada pelo Estatuto da Cidade, bem como os Planos Diretores Municipais, como instituições, pois são instrumentos que compõem um conjunto de regras formais da sociedade que restringem e habilitam a interação humana (North, 1990; Tang, 2011), configurando um padrão de controle para a conduta pessoal, que governam as relações e sobre as quais os atores orientam suas ações (Nee, 2005). Entretanto, o comportamento que se segue a partir das regras, ou seja, se as regras são ou não cumpridas, é o ponto mais importante para a realidade urbana que se apresenta.

Nos processos de planejamento e gestão urbanos, na produção e desenvolvimento do espaço urbano, é de vital importância ressaltar os aspectos informais. Neste sentido, é possível destacar a existência das regras informais que fornecem os modelos de comportamentos morais e cognitivos (Nee, 2005). Estes são estabelecidos por uma perspectiva cultural por meio de normas, hábitos, convenções e valores que refletem e moldam a ação dos atores (Hall \& Taylor, 2003; Hollingsworth, 2000). Complementa-se que essas regras formais definem que o processo de elaboração do Plano Diretor deve ser por meio do planejamento participativo e sua implementação pela gestão democrática, ambos processos ancorados em instituições participativas.

Na perspectiva do institucionalismo sociológico, Peter Evans (2003) construiu a noção de democracia deliberativa, que se refere a processos conjuntos de planejamento e solução de problemas, entendendo as 
instituições deliberativas ${ }^{1}$ como mais eficientes e eficazes e que, a longo prazo, melhor contribuiriam para o desenvolvimento deliberativo ${ }^{2}$. A análise aqui realizada parte do pressuposto que a democracia deliberativa de Evans (2003) serve como lente para análise da prática do planejamento urbano participativo e da gestão democrática das cidades preconizados pelo Estatuto da Cidade, que tem no Plano Diretor Participativo o principal instrumento de desenvolvimento urbano nos municípios. Assim, o estudo da democracia deliberativa se mostra útil na compreensão dos processos participativos referentes à elaboração e implementação de Planos Diretores.

Neste sentido, este artigo busca apresentar, à luz da democracia deliberativa (Evans, 2003), como se deram os processos de planejamento urbano participativo e gestão democrática em Palmas, na elaboração, aprovação e implantação do Plano Diretor Participativo de Palmas (TO)3.

Metodologicamente, foram realizadas pesquisas bibliográfica e documental. Como aporte teórico, foram revisados os conceitos de democracia deliberativa (Evans, 2003) e planejamento urbano participativo e da gestão democrática preconizados pelo Estatuto da Cidade (Maricato, 2011; Souza, 2010), buscando obter subsídios necessários para a análise. Para a coleta de dados, foram utilizadas como fontes primárias documentos disponibilizados pela prefeitura de Palmas em meio digital: os produtos realizados pela consultoria contratada para gerenciar o processo de elaboração do PDPP; as monografias de pós-graduação realizadas pelos técnicos e sociedade civil, que serviram de capacitação e leitura técnica; a Análise da Lei Complementar no 155/2007 (PDPP), feita pelo Instituto Municipal de Planejamento Urbano de Palmas (IMPUP) em virtude da Revisão do Plano Diretor, disponível no site oficial da revisão; leis municipais aprovadas, disponíveis no Banco de Leis do Município de Palmas. Houve ainda coleta de dados em fontes secundárias, em especial os trabalhos de Coriolano (2011) e Coriolano, Rodrigues e Oliveira (2013) que abordaram a aplicação de instrumentos urbanísticos no PDPP para a redução das desigualdades socioterritoriais.

As análises são apresentadas em etapas. Na primeira, com a elaboração e a aprovação final do PDPP em 2007. A segunda se refere à implantação do PDPP, enfatiza as instâncias deliberativas na gestão democrática e alterações do planejamento, chegando até o início do processo de revisão do plano, obrigatório a cada dez anos. Por fim, apresenta as considerações finais.

\section{Democracia deliberativa e o Estatuto da Cidade: um diálogo necessário}

Em seu estudo a respeito da democracia deliberativa, Evans (2003) compreende que o padrão das políticas públicas em países em desenvolvimento tem sido historicamente a insistência na "monocultura institucional"4, que se baseia em duas premissas: a primeira, de que a eficiência das instituições independe do ambiente sociocultural; a segunda, de que uma versão idealizada de instituições anglo-americanas seria ideal para o desenvolvimento local. 0 autor afirma que as organizações internacionais pregam a presunção de que "os países mais avançados já descobriram o melhor planejamento institucional para o desenvolvimento e de que sua aplicabilidade transcende culturas e circunstâncias nacionais" (Evans, 2003, p. 28).

Para fugir da armadilha da monocultura institucional e pensar estratégias alternativas ou complementares, seria preciso buscar instituições participativas como meta-instituições 5 que promovam e

\footnotetext{
${ }^{1}$ Evans (2003) defende a consolidação de instituições deliberativas como modo de ampliar a qualidade das instituições básicas de governança, reconhecendo que elas fornecem o meio adequado de se definir os objetivos do desenvolvimento de maneira coletiva.

2 Evans (2003) afirma que a ideia de desenvolvimento deliberativo é a teoria mais sofisticada de desenvolvimento ligada à visão que o reconhece como um processo de mudança institucional

${ }^{3}$ Em 2015 a administração municipal (2013-2016) iniciou o processo de Revisão do Plano Diretor e foi finalizado no Executivo em 14 de dezembro de 2017. Seguiu para aprovação no Legislativo no dia 29 de março de 2018. E a Lei Complementar no 400, de 2 de abril de 2018, foi sancionada pelo prefeito, instituindo o Plano Diretor Participativo do Município de Palmas (TO). Os acontecimentos relacionados à revisão do PDPP não serão objeto das análises realizadas neste artigo.

${ }^{4}$ Evans (2003) utiliza da analogia com a monocultura agrícola para definir monocultura institucional como a imposição de planejamentos institucionais uniformes, como versões idealizadas de instituições anglo-americanas em países do hemisfério sul de modo a transcender suas culturas e circunstâncias nacionais.

${ }^{5} 0$ termo meta-instituições é utilizado no sentido de afirmar que as instituições participativas podem agregar conhecimento local e contribuir para a consolidação de instituições melhores (Evans, 2003), ou seja, uma instituição que pode melhorar outras instituições.
} 
agreguem conhecimento local e, desse modo, construir instituições políticas melhores e adaptadas à realidade do ambiente sociocultural. De acordo com Evans (2003, p. 21), o elemento-chave para fomentar o desenvolvimento econômico e social seriam as instituições básicas de governança, como instituições deliberativas, que devem ser centrais em qualquer conceituação de desenvolvimento, levando à ideia de "desenvolvimento deliberativo".

Ainda, essas instituições seriam essenciais para o desenvolvimento em países pobres, por ajudarem a fornecer condições de governança, sendo possível aprimorar as capacidades de alcançar objetivos. A noção de "democracia deliberativa" ou "governança fortalecida pela participação" refere-se a um processo de planejamento, solução de problemas e estratégias envolvendo conjuntamente cidadãos comuns (Evans, 2003, p. 35-36).

A implantação desse tipo de processo deliberativo em escala suficientemente ampla, como a municipal, levaria ao desenvolvimento deliberativo. Para o autor, "o desenvolvimento deliberativo só tem alguma chance de êxito quando emerge da dinâmica de políticas locais" (Evans, 2003, p. 51), tendo no espaço urbano uma excelente escala de atuação. É nesse aspecto que a democracia deliberativa se mostra como lente para a análise das determinações do Estatuto da Cidade quanto ao planejamento urbano participativo e a gestão democrática.

Com o processo de redemocratização do Brasil, a Emenda Constitucional de Iniciativa Popular de Reforma Urbana foi apresentada e aprovada, o que garantiu a inclusão na Constituição de 1988 de um capítulo com dois artigos sobre a Política Urbana. A figura do Plano Diretor foi incluída na Carta Magna como um eixo central no texto, travando a aplicação direta dos instrumentos de reforma urbana, visto a necessidade de lei específica a ser aprovada nos municípios (Maricato, 2011). Para Souza (2010), a importância do Plano Diretor foi exagerada, deixando de lado uma análise social mais ampla. A própria participação popular, fator-chave para impulsionar a democratização do planejamento e da gestão, não foi priorizada, ficando omissa na Constituição.

Em 2001, após 13 anos de vigência da Constituição, foi aprovado no Congresso Nacional o Estatuto da Cidade (Brasil, 2001), que regulamentou a Política Urbana. A Constituição e o Estatuto da Cidade estabeleceram que todos os municípios brasileiros com mais de 20 mil habitantes deveriam elaborar um Plano Diretor Participativo, delineando assim uma série de mudanças na prática de planejamento e gestão urbanos a ser realizadas. O Plano Diretor Participativo Municipal constituiu-se como o principal instrumento legal de planejamento para o desenvolvimento urbano nas cidades brasileiras, e o Conselho de Desenvolvimento Urbano como o principal instrumento da gestão participativa, responsável por garantir a implantação do plano diretor.

O Estatuto da Cidade tratou também da "obrigatoriedade e as condições da participação direta no planejamento e na gestão das cidades. Fê-lo de maneira insistente, reiterando o princípio da participação várias vezes ao longo do corpo da lei" (Souza, 2004, p. 218), principalmente no que tange ao Art. 52, que traz o crime de improbidade administrativa para os prefeitos que não cumprirem os requisitos da obrigatoriedade da participação popular direta quando da elaboração do Plano Diretor (Brasil, 2001). Em 2003, foi criado o Ministério das Cidades (MCidades) ${ }^{6}$. Tonella (2013) afirma que a criação desse ministério teve importante significado, pois pela primeira vez propôs-se o tratamento integrado de todas as políticas urbanas, levando em consideração o uso e a ocupação do solo para tratar da habitação, do saneamento e dos transportes e mobilidade urbana. Em 2004, iniciou-se a Campanha Nacional de Sensibilização e Mobilização visando à elaboração e implementação de Planos Diretores Participativos, com o objetivo de construir cidades includentes, democráticas e sustentáveis. Para a formulação dessa campanha, considerou-se o prazo de cinco anos, que se encerrou em 2006.

Para o então MCidades, a obrigatoriedade da elaboração de Planos Diretores Participativos era uma oportunidade de ampliar a participação social, o debate e o conhecimento sobre cada município, uma vez que a coordenação do processo participativo de elaboração de um Plano Diretor deve ser compartilhada, por meio da efetiva participação do poder público e da sociedade civil, em todas as etapas do processo, desde a elaboração até a definição dos mecanismos para a tomada de decisões (Concidades, 2005). A participação era o instrumento que permitiria aos habitantes conhecer a cidade, entender as forças que a controlam e

\footnotetext{
${ }^{6}$ Por intermédio da Medida Provisória no 870, de 1ำ de janeiro de 2019, o Ministério das Cidades e o Ministério da Integração Nacional foram transformados no Ministério do Desenvolvimento Regional e o Conselho das Cidades, em Conselho Nacional de Desenvolvimento Urbano.
} 
incorporar os sujeitos ao processo político e ao seu controle. Com a aprovação do Estatuto da Cidade, houve a institucionalização do Plano Diretor Participativo como principal ferramenta de planejamento para alcançar o desenvolvimento urbano nas cidades brasileiras e o Conselho de Desenvolvimento Urbano como instrumento de gestão participativa, responsável por garantir a implantação do plano.

Nesse sentido, é possível realizar um paralelo entre os objetivos e métodos defendidos por Evans (2003) e pelo Estatuto da Cidade (Quadro 1), que representa o diálogo entre eles. Em ambos há o envolvimento de atores governamentais e de cidadãos comuns em processos participativos. Ambos reconhecem que somente instituições deliberativas têm plenas condições de promover e agregar o conhecimento local na construção de políticas urbanas mais adaptadas à realidade do ambiente sociocultural.

Quadro 1 - Síntese comparativa entre a teoria da democracia deliberativa e o Estatuto da Cidade

\begin{tabular}{|c|c|c|}
\hline & Democracia deliberativa & Estatuto da Cidade \\
\hline $\begin{array}{l}\text { Como são os processos } \\
\text { de planejamento e } \\
\text { gestão }\end{array}$ & $\begin{array}{l}\text { Processo de planejamento, solução de } \\
\text { problemas e estratégias envolvendo } \\
\text { conjuntamente cidadãos comuns (Evans, } \\
\text { 2003). }\end{array}$ & $\begin{array}{l}\text { Práticas de planejamento urbano e gestão } \\
\text { democrática previstas na Política Urbana Brasileira (Brasil, } \\
\text { 1988; 2001). }\end{array}$ \\
\hline $\begin{array}{l}\text { Objetivo } \\
\text { Meio }\end{array}$ & $\begin{array}{l}\text { Desenvolvimento deliberativo. } \\
\text { Instituições deliberativas. }\end{array}$ & $\begin{array}{l}\text { Desenvolvimento urbano. } \\
\text { Planejamento participativo através do Plano Diretor } \\
\text { Participativo e gestão democrática através do Conselho } \\
\text { de Desenvolvimento Urbano. }\end{array}$ \\
\hline $\begin{array}{l}\text { Escala } \\
\text { Participação }\end{array}$ & $\begin{array}{l}\text { Local / Municipal. } \\
\text { Entendida como "fim-em-si-mesmo", } \\
\text { enfatizado pelo enfoque de Amartya Sen. }\end{array}$ & $\begin{array}{l}\text { Municipal. } \\
\text { Permite aos habitantes conhecer a cidade, entender as } \\
\text { forças que a controlam, incorporar os sujeitos ao } \\
\text { processo político e ao seu controle. }\end{array}$ \\
\hline
\end{tabular}

Fonte: Elaboração dos autores (2019).

O Estatuto da Cidade prevê ainda, em seu art. 43, diversos instrumentos para garantir a gestão democrática da cidade: órgãos colegiados de política urbana nos níveis nacional, estadual e municipal; debates, audiências e consultas públicas; conferências sobre assuntos de interesse urbano nos níveis nacional, estadual e municipal; iniciativa popular de projeto de lei e de planos, programas e projetos de desenvolvimento urbano.

Assim, para obter uma governança fortalecida pela participação, além de práticas de planejamento participativo há espaços para o fomento da gestão democrática. Portanto, com essas duas ferramentas seria possível a solução de problemas e a proposição de estratégias envolvendo conjuntamente cidadãos comuns, o que levaria a um desenvolvimento urbano deliberativo.

\section{Elaboração e aprovação do PDPP à luz da democracia deliberativa}

A elaboração do Plano Diretor Participativo de Palmas (PDPP) buscou seguir a metodologia e as determinações do então Ministério das Cidades, bem como a Campanha Nacional do Plano Diretor. A elaboração do PDPP recebeu recursos do Banco Interamericano de Desenvolvimento, sob a coordenação do Ministério das Cidades e fiscalização da Caixa Econômica Federal. No pacote do Plano Estratégico Municipal para Assentamentos Subnormais (PEMAS) estava prevista a revisão do Plano Diretor Urbanístico de Palmas (PDUP), a Lei Ordinária no 468, de 6 de janeiro de 19947.

0 processo de elaboração do PDPP realizou-se a partir da contratação de uma consultoria chamada Associação para Recuperação e Conservação do Ambiente (ARCA), que realizou um curso de Pós-Graduação, Especialização em Planejamento Urbano e Ambiental, em parceria com Universidade Federal do Tocantins (UFT), envolvendo 50 pessoas entre os técnicos da Prefeitura Municipal e representantes da comunidade.

Coriolano (2011, p. 79) destaca que a intenção da Prefeitura Municipal e da consultoria na definição de sua metodologia de elaboração do PDPP "era a de capacitar os técnicos municipais e os representantes sociais

\footnotetext{
${ }^{7}$ A Lei Ordinária no 468/1994 é denominada Plano Diretor Urbanístico de Palmas, pois traz em seu escopo que os mapas e plantas relacionados ao projeto urbanístico de Palmas integrem a lei na forma de seus anexos. Entretanto, ela também dispõe sobre a divisão do solo do município para fins urbanos, configurando-se muito mais como a lei que oferece os parâmetros municipais para parcelamento do solo urbano do que um Plano Diretor, propriamente dito.
} 
de modo a proporcionar uma autonomia para que estes tivessem condições de implementá-lo". No Art. 3o do PDPP aparece expresso que sua elaboração teve como premissa básica o fortalecimento institucional do processo de planejamento e gestão do município, o envolvimento e a capacitação dos servidores efetivos e representações comunitárias e a ampla participação da sociedade.

Para a elaboração do PDPP, foram criados oito grupos de estudo para a estruturação de propostas com tema específico: habitação; uso do solo; infraestrutura; trânsito, transporte e mobilidade; meio ambiente; desenvolvimento econômico sustentável, geração de emprego e renda; Taquaruçu e Buritirana; gestão (Palmas, 2006a). A primeira fase, denominada Leitura Técnica e realizada sob a forma de uma monografia da pós-graduação em Planejamento Urbano e Ambiental, foi confrontada com as propostas oriundas da participação da população, que constituem a Leitura Comunitária.

A administração municipal demonstrou interesse em realizar o planejamento urbano de maneira participativa, concebendo instituições deliberativas. Foi realizado, de janeiro de 2005 a junho de 2006, um total de 41 atividades participativas entre oficinas, reuniões, apresentações, seminários, audiências, visitas técnicas, cursos, encontros, ciclos de debates e consultas públicas (Palmas, 2006a, 2006b). Destaca-se a apresentação em maio de 2015 do projeto do PDPP na Câmara, como primeira iniciativa de envolvimento dos vereadores no processo. 0 Plano de Comunicação (Palmas, 2005) ressalta a necessidade de discussão sobre o PDPP nas sessões ordinárias da Câmara Municipal.

Foram utilizados como estratégias de mobilização da sociedade os meios de comunicação de massa, além da produção de material impresso de divulgação e disponibilização do material produzido em locais de grande aglomeração de pessoas. Também foi enviado material informativo para ONGs, sindicatos, igrejas, clubes, associações e entidades de classe (Palmas, 2005).

Desse modo, ressalta-se o duplo caráter educativo desse processo: primeiro, sob o enfoque de Amartya Sen (2010), que tem no processo de participação o "fim-em-si-mesmo", neste caso expresso pela oportunidade de a comunidade conhecer a cidade e ser incorporada ao processo político decisório; segundo, com a promoção do curso de especialização, que capacitou diversos profissionais e membros da sociedade civil.

Mesmo não havendo um parâmetro consolidado quanto ao número ideal de participantes em audiências públicas, durante o processo de elaboração do PDPP a mobilização realizada pela Prefeitura não foi capaz de manter crescente a quantidade de participantes.

A partir dos depoimentos dos técnicos da Prefeitura e da visão dos Conselheiros percebeu-se que o grande número de reuniões realizadas tornou o processo exaustivo, fazendo com que a população deixasse de participar nas últimas etapas do processo, prejudicando principalmente o momento de envio do Plano à Câmara Municipal, que não contou com o necessário apoio da sociedade organizada (Coriolano, 2011, p. 82).

Coriolano et al. (2013) destacam a qualidade inovadora do processo, os avanços no planejamento urbano e sua importância como experiência participativa, contudo a falta de participação dos vereadores no processo participativo dificultou a aprovação integral do Projeto de Lei na Câmara Municipal. Assim, é possível resgatar o pensamento de Maricato (2011) sobre a dificuldade de aprovação dos instrumentos da política urbana por meio do Plano Diretor condicionado à lei municipal aprovada por vereadores. Nesse sentido, evidencia-se a natureza do poder municipal, executivo e legislativo, que tem na especulação imobiliária uma de suas maiores forças.

Ainda sobre esse aspecto, retoma-se a teoria do institucionalismo sociológico, que considera as questões sociais, históricas e culturais primordiais para o processo de desenvolvimento das instituições, a ressaltar neste contexto o processo deliberativo de elaboração do PDPP. Os estudos desenvolvidos pela pósgraduação, realizados por técnicos e sociedade civil, confirmados, alterados e aprovados nas diversas reuniões/audiências públicas, serviram de base para a elaboração de uma minuta de projeto de lei que representava os desejos e anseios da população. No entanto, na última instância de aprovação do PDPP, a Câmara de Vereadores, o projeto de lei sofreu alterações que comprometeram as deliberações democráticas.

Entre as principais alterações do projeto de lei apresentado à Câmara de Vereadores, encontram-se aquelas relativas às Zonas Especiais de Interesse Social (ZEIS) e ao perímetro urbano. No projeto de lei do PDPP, elaborado com base no diagnóstico da Leitura Técnica e da Leitura Comunitária, as áreas vazias no interior do perímetro urbano dotadas de infraestrutura foram categorizadas como ZEIS de dois tipos, a saber: 
- Tipo 1, as glebas urbanas, públicas ou particulares, para fins de loteamentos de interesse social, englobando as quadras: ARSO 12, ARSO 51, ARSO 71, ARSO 131, ARSO 141, ARSO 151, ARNE 71, ARNE 74, ALCNO 33, ALCNO 43, ARNO 14, ARSE 132, ARSE 151 e ARSE 152.

- Tipo 4, os Lotes Multifamiliares (HM), vazios e/ou subutilizados, com infraestrutura básica localizados em quadras dentro da Área de Ocupação Preferencial Avenida JK e da Área de Ocupação Preferencial Avenida Teotônio Segurado.

Das ZEIS propostas, somente constam no texto da Lei Complementar ${ }^{\circ} 155$, de 28 de dezembro de 2007, aprovada pela Câmara Municipal, as quadras ALCNO 33, ALCNO 43, ARSE 132 e ALCNO 13 (incluída pelos vereadores). Além de excluir diversas áreas destinadas às ZEIS do Tipo 1 , também excluiu na totalidade as ZEIS Tipo 4 (Figura 1).

\section{ZEIS tipo 1: Glebas urbanas para loteamento de interesse social e ZEIS tipo 4: Lotes Multifamiliares em área de ocupação preferencial}
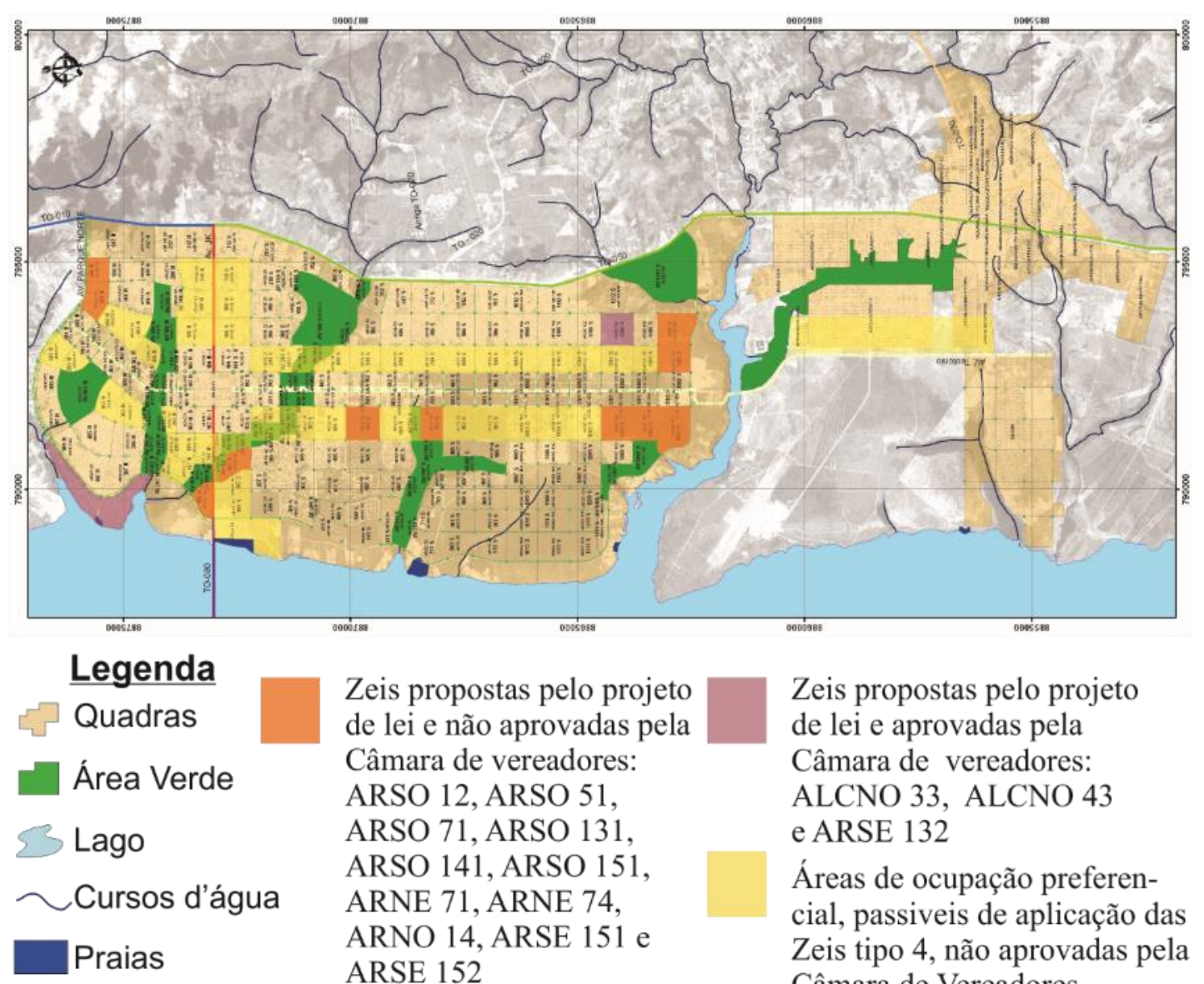

Zeis propostas pelo projeto de lei e não aprovadas pela Câmara de vereadores: ARSO 12, ARSO 51, ARSO 71, ARSO 131, ARSO 141, ARSO 151, ARNE 71, ARNE 74, ARNO 14, ARSE $151 \mathrm{e}$ ARSE 152

Zeis propostas pelo projeto de lei e aprovadas pela Câmara de vereadores: ALCNO 33, ALCNO 43 e ARSE 132

Áreas de ocupação preferencial, passiveis de aplicação das Zeis tipo 4, não aprovadas pela Câmara de Vereadores.

Figura 1 - Identificação no espaço das áreas definidas como ZEIS na elaboração e aprovação do Plano Diretor Participativo de Palmas. Fonte: Prefeitura Municipal de Palmas. Elaboração dos autores (2019).

Isso se deu porque as "áreas [passaram] por um intenso processo de valorização imobiliária e as que foram mantidas eram áreas de propriedade do Estado do Tocantins" (Coriolano et al., 2013, p. 141) e já tinham recursos aprovados do Programa de Aceleração do Crescimento (PAC), voltados para Habitação de Interesse Social (HIS).

Ao comparar o que foi excluído com o que foi apresentado pelo Executivo, verifica-se a intenção do Executivo municipal de promover a inclusão social, buscando ocupar os vazios urbanos. Contudo, assim como ocorre nos demais municípios brasileiros, o interesse privado do mercado tem mais peso que o interesse público, ou da coletividade, mantendo o acesso à terra urbanizada e à moradia cada vez mais difícil para a população de menor renda. 
Outra alteração feita no projeto de lei apresentado à Câmara de Vereadores diz respeito ao perímetro urbano. Mesmo sendo aprovada a redução do perímetro urbano em relação à Lei Complementar no 58/2002, que instituía o Macrozoneamento Territorial do Município de Palmas, a versão final do PDPP modificou o perímetro proposto no processo de elaboração participativo, acrescentando a Área de Urbanização de Interesse Turístico (AUIT).

A mencionada região foi posteriormente regulamentada pela Lei Complementar no 203/2010, que trata dos usos admitidos e índices urbanísticos da AUIT do município de Palmas. Essa lei foi alterada pela Lei Complementar no 269/2012, sem a participação popular nem aprovação em audiência pública. A criação dessa área teve como objetivo atender à demanda do mercado imobiliário e pode acarretar uma maior demanda por infraestrutura e equipamentos urbanos para o município (Coriolano et al., 2013).

As duas alterações se mostram como um desrespeito ao definido pelas instituições deliberativas, no exercício da democracia deliberativa. Nestes pontos, ao resultado das reuniões de planejamento participativo foram sobrepostos outros interesses atuantes na Câmara de Vereadores (Quadro 2). Estas alterações contrariam os ideais de desenvolvimento urbano e de desenvolvimento deliberativo defendidos pelo Estatuto da Cidade e por Evans (2003), respectivamente. A primeira alteração representa a dificuldade de inserção das famílias de baixa renda em áreas urbanizadas da cidade, com a manutenção da segregação socioespacial na produção do espaço urbano em Palmas, e a segunda reflete a prática da especulação imobiliária, que busca sempre a expansão do perímetro urbano, e a decorrente valorização da terra, com a finalidade de ampliar seus ganhos.

Quadro 2 - Síntese das alterações no projeto de lei aprovado na Câmara de Vereadores

\begin{tabular}{|c|c|}
\hline Alterações & Análise \\
\hline Diminuição de ZEIS & $\begin{array}{l}\text { Emenda ao projeto de lei realizado na Câmara de Vereadores. } \\
\text { Alteração da proposta negando as deliberações democráticas realizadas em instituições deliberativas }\end{array}$ \\
\hline Criação da AUIT & $\begin{array}{l}\text { populares. } \\
\text { Aprovação de novas leis complementares sem audiências públicas, ou seja, sem utilização de instituições } \\
\text { deliberativas populares. }\end{array}$ \\
\hline
\end{tabular}

Fonte: Elaboração dos autores (2019).

O que se observa é que o primeiro esforço de realização de um planejamento urbano participativo, por meio de instituições deliberativas populares, mesmo sendo consistente e frutífero, não foi capaz de garantir a consolidação e a aprovação do projeto de lei conforme elaborado originalmente. A aprovação final do projeto de lei se deu na Câmara de Vereadores, e estes ocasionaram alterações significativas à redação final da lei.

\section{Avaliação da implantação e da gestão do PDPP à luz da democracia deliberativa}

No dia 28 de dezembro de 2007, entrou em vigor a Lei Complementar no 155/2007, que dispõe sobre a política urbana do município de Palmas, formulada para atender ao pleno desenvolvimento das funções sociais da cidade e a garantia do bem-estar de seus habitantes, conforme estabelece a Constituição de 1988 em seus Arts. 182 e 183, e o Estatuto da Cidade. Entretanto, nem todas as ações e instrumentos previstos na elaboração do PDPP, por meio da democracia deliberativa, e aprovados pela Câmara de Vereadores foram implantados.

A análise da Lei Complementar no 155/2007 realizada pelo Instituto Municipal de Planejamento Urbano de Palmas, na ocasião da revisão do PDPP, ressalta que algumas leis específicas como a lei de parcelamento do solo urbano (Art. 19) e a lei de zoneamento de uso e ocupação do solo urbano (Art. 20) permaneceram defasadas e apresentam pouca efetividade, necessitando revisão (Palmas, 2016).

Outras ações como o enquadramento das unidades de conservação (UC) municipais (Art. 29), os estudos específicos de microzoneamento para a criação de parque linear urbano nas margens do lago de Palmas (Art. 31) e de microzoneamento para criação de locais de interesse turístico (Art. 32) tinham prazo máximo de dois anos para ser realizados, prazo não levado em consideração e não cumprido. 
O Sistema Municipal de Unidades de Conservação (SMUC) (Art. 41) não foi criado e tampouco foram definidas as categorias e delimitação das áreas. Apenas a UC do Entorno do Lago Lajeado foi criada ${ }^{8}$, todavia ainda sem plano de manejo aprovado. Somente em 2015 o Programa Iniciativa Cidades Emergentes e Sustentáveis, por meio do Plano de Ação Palmas Sustentável, estabeleceu diretrizes para a utilização das margens do lago de Palmas (Palmas, 2016), contudo ainda sem regulamentação para implantação.

Quanto às políticas setoriais, a referida análise destaca que somente as políticas de saneamento básico e regularização fundiária sustentável foram instituídas por lei e devidamente aprovadas, e o Plano Municipal de Mobilidade e o Plano Municipal de Arborização estão em fase de aprovação (Palmas, 2016). 0 Plano de Saneamento Básico foi instituído via Decreto no 700/2014, com o intuito de implementar as ações previstas no Art. 50, contudo, quanto ao manejo de resíduos sólidos, ressalta-se que o parágrafo único do referido artigo fixa o prazo máximo de um ano para a implantação da coleta seletiva de resíduos sólidos urbanos, o que nunca ocorreu.

O Programa de Regularização Fundiária Sustentável (Art. 100) foi criado com a Lei Ordinária no 2.225/2016. Foi desenvolvido como Plano de Regularização Fundiária Sustentável com recursos do governo federal, seguiu metodologia participativa, aprovação em audiência pública e apreciação do Conselho de Desenvolvimento Urbano e Habitação, em 2012. Vale destacar um lapso temporal de quatro anos desde a finalização e aprovação popular (audiência e conselho), em 2012, até a finalização da aprovação da câmara legislativa como lei em 2016, o que pode ter causado perdas na atualização das demandas e necessidades da população que participou da construção do documento.

No tocante à Política Habitacional prevista no Art. 70, a Prefeitura de Palmas desenvolveu, por meio de consultoria, a minuta do projeto de lei da Política Municipal de Habitação de Palmas (PMHP) e o Plano Local de Habitação de Interesse Social (PLHIS), em 2010. Ambos foram desenvolvidos por metodologia participativa. A PMHP chegou a ser aprovada pelo Conselho de Desenvolvimento Urbano e Habitação ${ }^{9}$ em 2012, porém não chegou a ser enviada para aprovação da Câmara de Vereadores através de lei complementar. O PLHIS não apresentava a necessidade de promulgação por lei, entretanto sua constante discussão e avaliação não foram implementadas (Palmas, 2016). Observa-se, desse modo, mais um lapso temporal de dois anos entre a elaboração em 2010 e a aprovação do conselho em 2012; considerando que a minuta do projeto de lei ainda não tinha sido enviada para a Câmara de Vereadores, somam-se mais quatro anos de lapso. 0 descaso com os prejuízos acarretados pela ausência de atualização das demandas e necessidades da população, que participou da construção do documento, indica a ineficiência dos processos administrativo e legislativo e a falta de interesse político na execução da política.

Entre os instrumentos previstos na elaboração do PDPP, aprovados pela Câmara de Vereadores e implantados, têm-se: o Parcelamento, Edificação ou Utilização Compulsórios (Art. 75), o Imposto sobre a Propriedade Predial e Territorial Urbana (IPTU) Progressivo no Tempo e a Desapropriação com Pagamento em Títulos (Art. 77) e a Outorga Onerosa do Direito de Construir e da Mudança de Uso (Art. 81). A Lei Complementar no 195/2009 dispõe sobre a regulamentação e aplicação do Parcelamento, Edificação e Utilização Compulsório (PEUC) do solo urbano não edificado, subutilizado ou não utilizado, instrumento que somente entrou em efetividade em 2013: ao todo, 600 imóveis vagos e 10 glebas já foram notificados desde então, sendo que 60 imóveis vagos retiraram alvará de construção e 4 glebas foram microparceladas (Palmas, 2016).

Quanto ao IPTU Progressivo, está previsto nos Arts. 63 a 65 do Código Tributário Municipal — Lei Complementar no 107, de 30 de setembro de 2005. Entretanto, somente foi regulamentado com a Lei Complementar no 195/2009. A análise da Lei Complementar no 155/2007 realizada pelo Instituto Municipal de Planejamento Urbano de Palmas destaca que o primeiro lançamento de IPTU Progressivo se deu no exercício de 2015, para 205 imóveis, que não atenderam às notificações de parcelamento ou edificação compulsórios. Em 2016, foram 310 lançamentos com IPTU Progressivo, sendo 161 imóveis com a primeira progressividade (alíquota de 3\%) e 149 com a segunda progressividade (alíquota de 6\%) (Palmas, 2016). A Desapropriação com Pagamento em Títulos, ainda que regulamentada pela Lei Complementar no 195/2009,

\footnotetext{
${ }^{8} 0$ decreto de 27 de dezembro de 2012 criou e denominou a área de Proteção Ambiental do Entorno do Lago do Lajeado, com um prazo de cinco anos para a realização do plano de manejo. Essa UC foi regulamentada somente como demanda levantada pelo Executivo para aprovação do processo de parcelamento das quadras lindeiras.

${ }^{9}$ Resolução Normativa 016/2012, aprova a minuta do projeto de lei que estabelece a Política Municipal de Habitação de Palmas.
} 
ainda não foi implementada porque sua aplicação somente acontecerá após os cinco primeiros anos de vigência do IPTU Progressivo.

Os instrumentos de Transferência do Direito de Construir (Art. 86), Operações Urbanas Consorciadas (Art. 87) e Direito de Preempção (Art. 88) não foram implantados. No documento de análise da Lei Complementar no 155/2007, consta que tais instrumentos não foram regulamentados devido à ausência de diretrizes e estudos específicos que viabilizem a definição e aplicação dos mesmos, evidenciando falta de interesse político em implantá-los.

A Outorga Onerosa do Direito de Construir e da Mudança de Uso foram regulamentadas pela Lei Complementar no 274/2012 (alterada pela Lei Complementar no 316/2015), entretanto tal instrumento tem apresentado problemas no que concerne à perfeita aplicabilidade, considerando as questões relativas aos estudos e relatórios de impacto de vizinhança (Palmas, 2016).

0 instrumento denominado Estudo Prévio de Impacto de Vizinhança (EIV) e seu respectivo Relatório de Impacto de Vizinhança (RIV) (Art. 89) chegaram a ser regulamentados pela Lei Complementar no 245/2012, que apenas quatro meses depois foi revogada pela Lei Complementar no 253/2012. Desse modo, o EIV/RIV não está devidamente regulamentado. 0 Instituto Municipal de Planejamento Urbano de Palmas afirma que, por recomendação da Procuradoria-Geral do município10, a Secretaria de Desenvolvimento Urbano Sustentável tem sido responsável por expedir diretrizes mínimas para os casos em que se exige EIV/RIV, como a Outorga Onerosa (Palmas, 2016).

A Lei Complementar no 253/2012 alterou o Art. 19 e o Art. 43 do PDPP, sem a devida transparência e a participação social preconizadas pelo Estatuto da Cidade. Com essa lei foi permitida a mudança de uso das áreas verdes e áreas públicas municipais. Inicialmente, o Art. 19, em seu § 3o, previa audiência pública para aprovação de alteração de áreas públicas nos parcelamentos, entretanto, a redação dada pela alteração desse artigo retirou essa obrigatoriedade. 0 Art. $43, \S 3^{\circ}$ estabelece que a aprovação de mobiliário e equipamentos comunitários para esporte, lazer e recreação em áreas verdes deverá ser feita caso a caso, pelos Conselhos Municipais de Desenvolvimento Urbano, Meio Ambiente e aqueles relacionados com o equipamento em questão, e submetida a audiência pública.

Quando trata da Participação Popular, o PDPP, em seu Art. 107, afirma que os programas urbanísticos das políticas setoriais serão debatidos com a comunidade interessada por meio dos mecanismos de gestão democrática, que são (Art. 106): I - conselhos municipais; II - fundos municipais; III - orçamento participativo; IV - audiências e consultas públicas; V - conferências municipais; VI - iniciativa popular de projetos de lei; VII - referendo popular; VIII - plebiscito. Mas não houve implementação de alguns instrumentos de gestão democrática, como o orçamento participativo, a iniciativa popular de projetos de lei, referendo popular e plebiscito, ou seja, ainda não houve a adoção de um modelo de gestão participativo integrado e de forma permanente (Palmas, 2016).

Quanto ao Monitoramento do PDPP, a Lei Complementar no 155/2007 traz em diversos artigos essa necessidade: o Art. 108 afirma que o município buscará em parceria com a comunidade instituir programas de monitoramento das normas urbanísticas e do plano; o Art. 109 reforça que a atribuição de monitoramento do Plano Diretor e da legislação urbanística complementar é do Conselho de Desenvolvimento Urbano e Habitação (CMDUH); o Art. 110 traz diretrizes para o monitoramento do PDPP, envolvendo divulgação, debate e esclarecimento acerca da cidade e seu desenvolvimento; o Art. 111 apresenta que a Conferência Municipal de Desenvolvimento Urbano tem o objetivo de avaliar a condução e os impactos do plano; os Arts. 112 e 113 afirmam que o Poder Executivo Municipal implantará o Sistema Municipal de Acompanhamento e Controle, vinculado ao órgão de planejamento territorial, com diversas atribuições.

Contudo, a análise da Lei Complementar no 155/2007 expressa que nenhumas dessas determinações foi implementada. 0 sistema de monitoramento das normas urbanísticas e do PDPP não foi instituído; o CMDUH não cumpre a atribuição de monitoramento do PDPP, pois não há nenhuma sistematização para essa ação; e o Sistema Municipal de Acompanhamento e Controle não foi implantado (Palmas, 2016). Oliveira \& Velasques (2017, p. 96-97) apontam que somente em 2010 o CMDUH aprovou seu Regimento Interno, cinco anos após a sua criação. Essa demora, na opinião das autoras, "certamente contribuiu para falhas no acompanhamento da implementação do Plano Diretor vigente durante os últimos anos, resultando em uma descontinuidade de seus trabalhos".

\footnotetext{
10 Parecer no 1.143/2014 SEMAJ-PGM (processo no 2013058517).
} 
Nas Disposições Finais e Transitórias, o PDPP trata da priorização de investimentos em sistema viário (Art. 114), fornecimento de energia, fornecimento de iluminação pública, pavimentação asfáltica no interior de quadras (Art. 115). Sobre esse último ponto, observa-se uma implantação parcial das atividades. No documento de análise da Lei Complementar no 155/2007, consta que três dos cinco trechos indicados como prioritários no PDPP para duplicação de avenidas não foram previstos em nenhum programa devido à priorização de outras metas e ausência de demanda específica. Como se o próprio PDPP, nesses artigos, não gerasse por si só a demanda necessária pela priorização do investimento nessas áreas. A mesma justificativa é apresentada para a não realização de cinco trechos de abertura de sistema viário. Para a não pavimentação dos setores Irmã Dulce e União Sul, a justificativa é que os loteamentos não foram regularizados, atribuição também do Poder Executivo.

Assim, ao analisar o período de vigência do PDPP, observa-se que diversos itens aprovados na lei não foram implementados de maneira eficiente pelo Executivo municipal, o que demonstra desrespeito à proposta construída por meio das instituições deliberativas, no exercício da democracia deliberativa. No momento de implementar a política e seus instrumentos de desenvolvimento urbano, a gestão municipal não se mostrou eficiente, contrariando além dos ideais de desenvolvimento urbano defendidos pelo Estatuto da Cidade, também os ideias do desenvolvimento deliberativo, expresso por Evans (2003) (Quadro 3).

Quadro 3 - Síntese da implantação do Plano Diretor Participativo de Palmas (TO)

\begin{tabular}{|c|c|}
\hline Itens & Siłuação / Análise \\
\hline $\begin{array}{l}\text { Revisão de leis de parcelamento e ordenamento } \\
\text { urbano }\end{array}$ & \multirow{2}{*}{$\begin{array}{c}\text { Não regulamentado no prazo de } 2 \text { anos. } \\
\text { Desrespeito à proposta construída por meio de instituições deliberativas } \\
\text { populares. }\end{array}$} \\
\hline $\begin{array}{c}\text { Regulamentação das UCs, parque linear, área de } \\
\text { interesse turístico }\end{array}$ & \\
\hline $\begin{array}{c}\text { Políticas Setoriais - Plano de Regularização } \\
\text { Fundiária }\end{array}$ & $\begin{array}{c}\text { Elaborado de maneira participativa em } 2012 \text { e aprovado na câmara de } \\
\text { vereadores em 2017, podendo haver perdas na atualização das demandas, } \\
\text { definidas por meio de instituições deliberativas populares. }\end{array}$ \\
\hline Políticas Setoriais - Política de Habitação & $\begin{array}{c}\text { Elaborada de maneira participativa em 2010, aprovada pelo CMDUH em } 2012 . \\
\text { Não encaminhada para aprovação na câmara de vereadores, podendo } \\
\text { haver perdas nas definições realizadas por meio de instituições deliberativas } \\
\text { populares. }\end{array}$ \\
\hline PEUC & \multirow{2}{*}{$\begin{array}{l}\text { Lei aprovada em 2009, entrou em efetividade em } 2013 \text {. } \\
\text { Implementação ainda incipiente das deliberações democráticas. }\end{array}$} \\
\hline IPTU Progressivo & \\
\hline Desapropriação com Pagamento em Títulos & $\begin{array}{l}\text { Lei aprovada em 2009, aguardando implementação } \\
\text { Implementação ainda incipiente das deliberações democráticas. }\end{array}$ \\
\hline $\begin{array}{l}\text { Transferência do Direito de Construir, Operações } \\
\text { Urbanas Consorciadas e Direito de Preempção }\end{array}$ & $\begin{array}{c}\text { Não implantados. } \\
\text { Desrespeito à proposta construída por meio de instituições deliberativas } \\
\text { populares. }\end{array}$ \\
\hline Priorização de investimentos & $\begin{array}{l}\text { A pavimentação em diversas áreas não foi priorizada. } \\
\text { Implementação ainda incipiente das deliberações democráticas. }\end{array}$ \\
\hline $\begin{array}{l}\text { Outorga Onerosa do Direito de Construir e } \\
\text { Mudança de Uso }\end{array}$ & $\begin{array}{l}\text { Lei aprovada em 2012, entretanto falta regulamentação do EIV. } \\
\text { Implementação ainda incipiente das deliberações democráticas. }\end{array}$ \\
\hline Alterações na lei do PDPP após sua aprovação & $\begin{array}{c}\text { Artigos } 43 \text { e 19, sem promover audiências públicas. } \\
\text { Negação das instituições deliberativas populares como meio para o } \\
\text { planejamento continuado. }\end{array}$ \\
\hline Espaços da gestão democrática & $\begin{array}{l}\text { Espaços pouco consolidados e CMDUH enfraquecido. } \\
\text { Negação das instituições deliberativas populares como meio para o } \\
\text { planejamento continuado e gestão participativa e democrática. }\end{array}$ \\
\hline
\end{tabular}

Fonte: Elaboração dos autores (2019).

Desse modo, é possível afirmar que houve um aparente descaso com a gestão democrática do PDPP, mesmo com a criação do CMDUH, seja por falta de interesse do Executivo municipal ou pela ausência de pressão popular para a implantação desses espaços. Isso demonstrou fragilidade na efetivação do planejamento urbano em Palmas como um processo de governança fortalecida pela participação, por meio dos mecanismos e instrumentos contínuos de implantação e monitoramento das determinações do plano. 


\section{Considerações finais}

Este artigo cumpre seu objetivo de apresentar, à luz da democracia deliberativa (Evans, 2003), como se deram os processos de planejamento urbano participativo e gestão democrática em Palmas, na elaboração, aprovação e implantação do Plano Diretor Participativo de Palmas (T0). Ao reconhecer o entendimento de que o Estatuto da cidade e os planos diretores são instituições este artigo possibilita a utilização do estudo de Evans (2003) como referencial teórico. As análises aqui realizadas contribuem teoricamente para demostrar que o conceito, o objetivo, os meios de ação e escala da democracia deliberativa se mostram úteis na compreensão dos processos participativos referentes à elaboração e implementação de Planos Diretores. Existindo entre essas duas teorias um diálogo necessário a ampliação da compreensão dos processos relacionados ao desenvolvimento urbano deliberativo.

Por meio da pesquisa empírica, foi possível concluir que a metodologia de elaboração do PDPP se enquadrou em uma prática de planejamento urbano participativa, concebendo instituições de democracia deliberativa por meio das reuniões e audiências públicas, no entanto os espaços de gestão democrática não se consolidaram, inviabilizando uma governança fortalecida pela participação.

Destaca-se que a metodologia de elaboração e o seu duplo caráter educativo - o processo de participação popular nas audiências como instituições deliberativas e a promoção do curso de especialização e capacitação de profissionais e membros da sociedade civil - parecem demonstrar o interesse da administração municipal (2005-2008) em realizar o planejamento urbano de maneira participativa. A Prefeitura Municipal e a consultoria contratada buscaram capacitar os técnicos municipais e os representantes sociais de modo a lhes proporcionar autonomia para que tivessem condições de implementar o PDPP, ou seja, dar continuidade aos processos de democracia deliberativa definidos pela gestão democrática. Essa foi uma estratégia pertinente, em conformidade com a teoria da governança fortalecida pela participação, no sentido de que o hábito de participar constrói cidadãos mais participativos.

Entretanto, a descontinuidade do processo participativo após a aprovação do PDPP demonstrou que, mesmo pertinente, a elaboração do Plano Diretor, por meio de instituição deliberativa, não foi suficiente para garantir os espaços de gestão democrática, inviabilizando uma governança fortalecida pela participação. 0 Conselho de Desenvolvimento Urbano e Habitação, principal instituição deliberativa da gestão democrática não se consolidou como uma instituição básica de governança capaz de fomentar um desenvolvimento urbano deliberativo.

O modelo de planejamento urbano participativo e gestão democrática, implantado após a aprovação do Estatuto da Cidade, encontra muitas dificuldades em seu processo de consolidação e produção de espaços urbanos mais justos e inclusivos. Seja dificuldades na institucionalização dos espaços democráticos de deliberação, de planejamento e gestão popular, ou pela cidadania pouco fortalecida e em construção da sociedade brasileira, ainda pouco compromissada com a função social da cidade e da propriedade urbana.

Por exemplo, as duas grandes alterações no Projeto de Lei do PDPP realizadas na Câmara de Vereadores (ZEIS e AUIT) ressaltam que a própria institucionalidade do processo, que atribui a necessidade de aprovação do Plano Diretor como lei complementar a ser submetida ao Legislativo, parece reduzir a força e a capacidade de ação da população em seu processo de participação direta. Essas duas alterações se destacam por representar a dificuldade de inserção das famílias de baixa renda em áreas urbanizadas da cidade, sugerindo a manutenção da segregação socioespacial na produção do espaço urbano em Palmas. Ainda, por reforçar a prática da especulação imobiliária, que busca sempre a expansão do perímetro urbano, com a finalidade de ampliar seus ganhos ante a valorização da terra urbana. Esses processos socioespaciais intraurbanos são fortes expressões de um planejamento urbano excludente, que ignora a construção coletiva e participativa de políticas públicas urbanas, o conhecimento local e a realidade do ambiente sociocultural, portanto, contrário ao desenvolvimento deliberativo.

Ao analisar os anos de vigência do PDPP, a questão das instituições democráticas de deliberação pouco fortalecidas chama mais uma vez a atenção. Os diversos espaços de gestão democrática previstos no PDPP, como o Conselho de Desenvolvimento Urbano e outros, não receberam a aderência necessária da sociedade em prol de seu fortalecimento e tampouco foram alvo de interesse da sociedade civil organizada na busca por seus direitos. 0 objetivo de controle social popular sobre o Estado ainda não aparece consolidado no caso da democracia deliberativa do PDPP e, nesse sentido, se faz necessário reforçar o papel do cidadão nos 
processos de participação e gestão urbanos, visto que o processo participativo é também emancipatório e educativo.

\section{Referências}

Brasil. (1988). Constituição Federal do Brasil. Brasília: Senado Federal.

Brasil. (2001). Estatuto da Cidade - Lei Federal no 10.257. Regulamenta os artigos 182 e 183 da Constituição Federal, que estabelecem diretrizes gerais da política urbana e dão outras providências. Brasília: Senado Federal.

Concidades. (2005). Resolução n 25, de 18 de março de 2005, do Conselho das Cidades. Brasília: Ministério das Cidades.

Coriolano, G. P. (2011). Plano Diretor Participativo de Palmas: análise da aplicação de instrumentos urbanísticos para a redução das desigualdades socioterritoriais (Dissertação de mestrado). Programa de Pós-graduação em Desenvolvimento Regional, Universidade Federal do Tocantins, Palmas.

Coriolano, G. P., Rodrigues, W. \& Oliveira, A. F. de. (2013). Estatuto da Cidade e seus instrumentos de combate às desigualdades socioterritoriais: o Plano Diretor Participativo de Palmas (T0). Urbe, Revista Brasileira de Gestão Urbana, 5(2), p. 131-145. http://dx.doi.org/10.7213/urbe.05.002.AC04.

Evans, P. (2003). Além da "monocultura institucional”: instituições, capacidades e desenvolvimento deliberativo. Sociologias, 5(9), p. 20-63. https://dx.doi.org/10.1590/S1517-45222003000100003.

Hall, P. A. \& Taylor, R. C. R. (2003). As três versões do neo-institucionalismo. Lua Nova, 58, p. 193-223. http://dx.doi.org/10.1590/S0102-64452003000100010.

Hollingsworth, J. R. (2000). Doing institutional analysis: implications for the study of innovations. Review of International Political Economy, 7(4), p. 595-644.

Maricato, E. (2011). Impasse da política urbana no Brasil. Petrópolis: Vozes.

Nee, V. (2005). The new institutionalisms in economics and sociology. In: Smelser, N. J. \& Swedberg, R. (Eds.). The handbook of economic sociology (2a ed.). New York: Princeton University Press.

North, D. (1990). Instituciones, cambio institucional y desempeño económico. Cidade do México: Fondo de Cultura Económica.

Palmas. (2005). Plano de Comunicação e Marketing do Plano Diretor Participativo de Desenvolvimento Territorial do Município de Palmas. ARCA. Secretaria Municipal de Desenvolvimento Urbano e Habitação. Arquivo digital disponibilizado pela Prefeitura Municipal de Palmas.

Palmas. (2006a). Relatório da leitura comunitária I. Secretaria Municipal de Desenvolvimento Urbano e Habitação. Diretoria de Planejamento Territorial. Arquivo digital disponibilizado pela Prefeitura Municipal de Palmas.

Palmas. (2006b). Relatório - Consultas Públicas. Secretaria Municipal de Desenvolvimento Urbano e Habitação. Diretoria de Planejamento Territorial. Arquivo digital disponibilizado pela Prefeitura Municipal de Palmas.

Palmas. (2016). Análise da Lei Complementar no 155/2007, Plano Diretor Participativo de Palmas. Instituto Municipal de Planejamento Urbano de Palmas. Recuperado em 6 de novembro de 2016, de http://planodiretor.palmas.to.gov.br/media/arquivos/9e40cd18fb114e498ecff299587c2da4.pdf

Oliveira, L. A. \& Velasques, A. B. A. (2017). 0 atual processo de revisão do Plano Diretor Participativo de Palmas/TO: considerações sob a ótica do Estatuto da Cidade. In: Bazolli, J. A., Oliveira, M. C. A. de \& Sousa, T. O. (Org.) O papel da extensão universitária como indutora da participação social: Palmas Participa! Palmas: EDUFT.

Sen, A. (2010). Desenvolvimento como liberdade. São Paulo: Companhia das Letras.

Sousa, A. P. de. (2014). Influência da mudança institucional na formação e organização da estrutura de governança e accountability do saneamento básico: um olhar para Goiás (Tese de doutorado). Programa de Pós-graduação em Políticas Públicas, Estratégias e Desenvolvimento, Universidade Federal do Rio de Janeiro, Rio de Janeiro. 
Souza, M. L. (2004). Participação popular no planejamento e na gestão orçamentária municipal no Brasil: um balanço e algumas questões. In: Harmanns, K. Participação cidadã: novos conceitos e metodologias. Fortaleza: Expressão Gráfica e Editora.

Souza. (2010). Mudar a cidade: uma introdução crítica ao planejamento e à gestão urbanos (7a ed.). Rio de Janeiro: Bertrand Brasil.

Tang, S. A (2011) General Theory of Institutional Change. London: Routledge.

Tonella, C. (2013). Políticas urbanas no Brasil: marcos legais, sujeitos e instituições. Revista Sociedade e Estado, 28(1), p. 29-52. http://dx.doi.org/10.1590/S0102-69922013000100003.

Editor responsável: Fábio Duarte

Recebido: Mar. 25, 2019

Aprovado: Ago. 24, 2019 